\title{
O impacto econômico das marcas e patentes no desempenho econômico das firmas industriais
}

\author{
Francisco Luna* \\ Adriano Baessa* \\ Gustavo Costa ${ }^{* * *}$ \\ Fernando Freitas ${ }^{* * *}$
}

A qualidade da regulamentação governamental é fator fundamental para a otimização dos gastos do setor produtivo e para a atração de novos investimentos. As discussões em torno desse tema assumem destaque cada vez maior entre empresários e governo. A propriedade intelectual, um dos pilares de um ambiente regulatório moderno, é avaliada e protegida pelo Estado. No Brasil, a instituição encarregada de avaliar e conceder tal propriedade é o Instituto Nacional de Propriedade Industrial (INPI).

A presente nota é resultado de um estudo conjunto do IPEA e do INPI. A proposta deste estudo é mensurar o impacto das marcas e patentes sobre o desempenho econômico das firmas. Para tanto, contamos com um amplo espectro de informações econômicas para serem relacionadas à base de depositantes de marcas e patentes no INPI. Iniciaremos a discussão com um breve perfil de marcas e patentes no Brasil para, então, discutir seu impacto no desempenho econômico das firmas.

\section{Perfil de marcas e patentes no Brasil}

Como se pode observar na tabela a seguir, a demanda pela proteção de marcas, medida pela quantidade de depósitos, aumentou 65\% no período 1994-2003. Porém, enquanto os depósitos cresceram, as concessões seguiram o caminho inverso. Em primeira análise, portanto, a estrutura do INPI se deteriorou concomitantemente aos estímulos de acordos internacionais que visavam uma aplicação mais rigorosa de leis de propriedade intelectual e de incrementos na própria demanda de mercado por registros de marcas. Observa-se ainda que o crescimento na demanda por patentes foi ainda maior, de $74 \% \mathrm{em}$ igual período. Em ambos os casos, esse crescimento não é contínuo, refletindo, possivelmente os efeitos externos, como o desempenho da economia, sobre esse indicador.

\footnotetext{
* Técnico de Planejamento e Pesquisa da Diretoria de Estudos Setoriais (Diset) do Ipea. Endereço eletrônico: francisco.santos@ipea.gov.br

** Técnico de Planejamento e Pesquisa da Diretoria de Estudos Setoriais (Diset) do Ipea. Endereço eletrônico: adriano.baessa@ipea.gov.br

*** Consultor da Diretoria de Estudos Setoriais (Diset) do Ipea.

**** Consultor da Diretoria de Estudos Setoriais (Diset) do Ipea.
} 
Tabela 1. Quantidade de depósitos e concessões de marcas e patentes por ano

\begin{tabular}{cccc}
\hline \multirow{2}{*}{ Ano } & \multicolumn{2}{c}{ Marcas } & Patentes \\
\cline { 2 - 4 } & Depósitos & Concessões & Depósitos \\
\hline 1994 & 53115 & 20744 & 13122 \\
1995 & 71235 & 23295 & 16325 \\
1996 & 64103 & 28153 & 18432 \\
1997 & 70483 & 26126 & 21889 \\
1998 & 69600 & 23614 & 21947 \\
1999 & 85675 & 37964 & 24309 \\
2000 & 96886 & 15708 & 24585 \\
2001 & 92519 & 18031 & 24442 \\
2002 & 86592 & 15200 & 23202 \\
2003 & 87598 & 9441 & 22837 \\
\hline
\end{tabular}

Fonte: INPI, 2005; IBGE, 2005 (elaboração própria).

Obs: Não temos as informações de concessões de patentes.

Analisando a tabela 2, a parcela de pessoas jurídicas (PJ) como depositantes de marcas se mantém aproximadamente constante ao longo do tempo. Somente a partir da década de 1990, os depósitos de marcas por parte de pessoas físicas (PF) passaram a ser expressivos. Isto ocorreu em detrimento da parcela de firmas estrangeiras sem CNPJ, representada pela legenda "Outros". O crescimento da proporção de PF no total, no decorrer do tempo, aponta para um menor grau de institucionalização dos demandantes de marcas.

Quanto às patentes, de acordo com Motta (1999) ${ }^{23}$, três hipóteses podem explicar a alta proporção de indivíduos como depositantes de patentes. O primeiro se refere à possibilidade de se tratar de pequenos empreendedores. A segunda é relacionada a problemas institucionais em diferenciar o que é público e o que é privado. Neste caso, pesquisas financiadas com recursos públicos podem ser apropriadas indevidamente por seu autor. Finalmente, pode ser um sinal de subdesenvolvimento.

Analisando a mesma tabela, vemos que o percentual de PF é considerável. Uma análise mais imediata indica que as duas últimas hipóteses devem se aplicar ao caso brasileiro. Medidas de curto prazo podem ajudar a superar o problema institucional. A questão do nível de desenvolvimento é mais complexa devendo ser analisada de forma mais abrangente.

\footnotetext{
${ }^{23}$ Albuquerque, Eduardo da Motta. Domestic Patents and Developing Countries: Arguments for their Study and Data from Brazil (1980-1995), UFMG/CEDEPLAR, Texto para Discussão 127, 1999.
}

100 
Tabela 2. Distribuição de depósitos de marcas por tipo de depositante, por ano (\%)

\begin{tabular}{cccccc}
\hline \multirow{2}{*}{ Ano } & \multicolumn{3}{c}{ Marcas } & \multicolumn{2}{c}{ Patentes } \\
\cline { 2 - 6 } & $\begin{array}{c}\text { Pessoa } \\
\text { Jurídica (PJ) }\end{array}$ & $\begin{array}{c}\text { Pessoa } \\
\text { Física (PF) }\end{array}$ & Outros & $\begin{array}{c}\text { Pessoa } \\
\text { Física (PF) }\end{array}$ & $\begin{array}{c}\text { Pessoa } \\
\text { Jurídica (PJ) }\end{array}$ \\
\hline 1990 & $92,3 \%$ & $5,9 \%$ & $1,8 \%$ & $60,1 \%$ & $39,9 \%$ \\
1991 & $91,4 \%$ & $6,5 \%$ & $2,0 \%$ & $69,7 \%$ & $30,3 \%$ \\
1992 & $89,8 \%$ & $8,4 \%$ & $1,8 \%$ & $67,7 \%$ & $32,3 \%$ \\
1993 & $91,4 \%$ & $6,8 \%$ & $1,8 \%$ & $69,4 \%$ & $30,6 \%$ \\
1994 & $89,9 \%$ & $8,4 \%$ & $1,7 \%$ & $71,2 \%$ & $28,8 \%$ \\
1995 & $88,3 \%$ & $9,3 \%$ & $2,4 \%$ & $73,8 \%$ & $26,2 \%$ \\
1996 & $85,3 \%$ & $12,1 \%$ & $2,6 \%$ & $73,2 \%$ & $26,8 \%$ \\
1997 & $83,8 \%$ & $13,4 \%$ & $2,8 \%$ & $72,2 \%$ & $27,8 \%$ \\
1998 & $83,6 \%$ & $12,9 \%$ & $3,4 \%$ & $70,5 \%$ & $29,5 \%$ \\
1999 & $84,4 \%$ & $11,5 \%$ & $4,0 \%$ & $71,3 \%$ & $28,7 \%$ \\
2000 & $85,8 \%$ & $10,2 \%$ & $4,1 \%$ & $70,7 \%$ & $29,3 \%$ \\
2001 & $87,5 \%$ & $8,0 \%$ & $4,5 \%$ & $71,0 \%$ & $29,0 \%$ \\
2002 & $88,6 \%$ & $6,4 \%$ & $5,0 \%$ & $68,3 \%$ & $31,7 \%$ \\
2003 & $88,5 \%$ & $6,2 \%$ & $5,3 \%$ & $66,0 \%$ & $34,0 \%$ \\
\hline
\end{tabular}

Fonte: INPI, 2005; IBGE, 2005 (elaboração própria).

A denominação outros se refere a depositantes estrangeiros.

Com o auxílio dos dados do Banco Central, é possível verificar se o capital controlador das firmas é nacional ou estrangeiro ${ }^{24}$. A análise da tabela 3 mostra uma queda na participação das firmas de capital estrangeiro para aproximadamente 5\% do total de firmas que depositam marcas no INPI. Vimos que em todos os anos a participação de marcas nacionais superava 90\%. No ano de 2003, 49\% dos depósitos foram nacionais enquanto que, em 1998, esse percentual era de 32\% somente. Albuquerque (1999) ressalta o papel importante das firmas nacionais como depositárias de patentes como característica fundamental de um sistema nacional dinâmico, não corroborada à luz dos dados brasileiros.

${ }^{24}$ A firma é considerada estrangeira se mais de 50\% de seu capital é estrangeiro e a sua identificação é feita a partir dos oito primeiros dígitos do CNPJ. 
Tabela 3. Distribuição de depósitos de marcas por origem de capital, por ano (\%)

\begin{tabular}{ccccc}
\hline \multirow{2}{*}{ Ano } & \multicolumn{2}{c}{ Marcas } & \multicolumn{2}{c}{ Patentes } \\
\cline { 2 - 5 } & Nacionais & Estrangeiras & Nacionais & Estrangeiras \\
\hline 1990 & $93,0 \%$ & $7,0 \%$ & $51,5 \%$ & $48,5 \%$ \\
1991 & $92,9 \%$ & $7,1 \%$ & $53,9 \%$ & $46,1 \%$ \\
1992 & $92,0 \%$ & $8,0 \%$ & $48,9 \%$ & $51,1 \%$ \\
1993 & $94,4 \%$ & $5,6 \%$ & $50,0 \%$ & $50,0 \%$ \\
1994 & $94,0 \%$ & $6,0 \%$ & $45,4 \%$ & $54,6 \%$ \\
1995 & $94,8 \%$ & $5,2 \%$ & $45,0 \%$ & $55,0 \%$ \\
1996 & $94,5 \%$ & $5,5 \%$ & $38,1 \%$ & $61,9 \%$ \\
1997 & $94,8 \%$ & $5,2 \%$ & $32,8 \%$ & $67,2 \%$ \\
1998 & $92,9 \%$ & $7,1 \%$ & $32,2 \%$ & $67,8 \%$ \\
1999 & $94,5 \%$ & $5,5 \%$ & $34,5 \%$ & $65,5 \%$ \\
2000 & $93,1 \%$ & $6,9 \%$ & $36,5 \%$ & $63,5 \%$ \\
2001 & $93,9 \%$ & $6,1 \%$ & $39,3 \%$ & $60,7 \%$ \\
2002 & $95,0 \%$ & $5,0 \%$ & $44,1 \%$ & $55,9 \%$ \\
2003 & $94,9 \%$ & $5,1 \%$ & $49,0 \%$ & $51,0 \%$ \\
\hline
\end{tabular}

Fonte: INPI, 2005; IBGE, 2005 (elaboração própria).

Uma patente pode diferir significativamente em termos do grau de tecnologia. Um registro de desenho industrial, por exemplo, é emitido quando uma nova embalagem é criada. Um modelo de utilidade é uma aplicação industrial para uma patente de invenção já criada.

Tabela 4. Distribuição de tipos de patente de 2000 até 2003

\begin{tabular}{lcccc}
\hline Tipo de Patente & 2000 & 2001 & 2002 & 2003 \\
\hline Desenho Industrial & $14,7 \%$ & $15,5 \%$ & $18,6 \%$ & $21,9 \%$ \\
Modelo deutilidade & $13,0 \%$ & $13,9 \%$ & $14,8 \%$ & $15,2 \%$ \\
Invenção & $72,3 \%$ & $70,6 \%$ & $66,6 \%$ & $62,9 \%$ \\
\hline Fonte: INPI, 2005; IBGE, 2005 (elaboração própria).
\end{tabular}

A Tabela 4 mostra que invenções representaram mais de 60\% dos depósitos de patentes desde 2000. Apesar de o indicador apresentar declínio, não é possível afirmar que se trata de uma tendência ou somente um efeito temporário.

\section{O impacto econômico das marcas e patentes}

Para se identificar as diferentes estratégias de marcas e patentes, separamos as firmas em quatro categorias, considerando todas as possíveis combinações de depositantes (ou não) em cada no.

A tabela 5 confirma o pequeno grau de institucionalização da propriedade de marcas no país. Em 1998, 86\% das firmas industriais não possuíam marcas ou patentes. Em 2002, este percentual pouco se alterou. Obviamente, tal informação deve ser anunciada sem alarde, 102 
dado o curto tempo observado, e deve ser ponderada pelo fato de que nem todas as firmas que depositam marcas no INPI são captadas pelo IBGE, o caso de firmas estrangeiras, e nem todas as que criam e usam marcas e patentes, as depositam no INPI.

Tabela 5. Distribuição percentual de firmas da PIA (indústria) por estratégia de marcas e patentes, 1998-2002

\begin{tabular}{lccccc}
\hline Estratégia & 1998 & 1999 & 2000 & 2001 & 2002 \\
\hline $\begin{array}{l}\text { Não depositaram marcas } \\
\text { ou patentes }\end{array}$ & $85,94 \%$ & $84,69 \%$ & $84,14 \%$ & $84,22 \%$ & $85,57 \%$ \\
$\begin{array}{l}\text { Depositaram somente } \\
\text { marcas }\end{array}$ & $11,71 \%$ & $12,68 \%$ & $13,30 \%$ & $13,42 \%$ & $11,94 \%$ \\
$\begin{array}{l}\text { Depositaram somente } \\
\text { patentes }\end{array}$ & $1,20 \%$ & $1,48 \%$ & $1,32 \%$ & $1,29 \%$ & $1,48 \%$ \\
$\begin{array}{l}\text { Depositaram marcas e } \\
\text { patentes }\end{array}$ & $1,15 \%$ & $1,14 \%$ & $1,25 \%$ & $1,07 \%$ & $1,01 \%$ \\
Total & $100 \%$ & $100 \%$ & $100 \%$ & $100 \%$ & $100 \%$ \\
\hline
\end{tabular}

Fonte: INPI, 2005; IBGE, 2005 (elaboração própria).

O passo seguinte foi explorar as variáveis econômicas mais relevantes na tentativa de encontrar as principais características das firmas que possuem marcas. Os valores financeiros informados na tabela foram deflacionados.

Tabela 6. Médias de algumas variáveis econômicas de firmas da PIA (indústria) por estratégia de marcas, 1998-2002

\begin{tabular}{llccccc}
\hline Estratégia & Variaveis & 1998 & 1999 & 2000 & 2001 & 2002 \\
\hline Não depositaram & VTI (R \$ milhões) & 3,92 & 4,44 & 5,18 & 5,4 & 5,89 \\
Marcas ou & Pessoal ocupado & 119 & 119 & 124 & 118 & 118 \\
Patentes & Tempo de estudo & 6,72 & 6,92 & 7,1 & 7,3 & 7,5 \\
\hline \multirow{2}{*}{ Depositaram } & VTI (R \$ milhões) & 15,5 & 16,16 & 16,52 & 20,97 & 23,68 \\
Apenas Marcas & Pessoal ocupado & 306 & 287 & 282 & 298 & 302 \\
& Tempo de estudo & 7,42 & 7,64 & 7,91 & 8,07 & 8,29 \\
\hline Depositaram & VTI (R $\$$ milhões) & 37,22 & 37,89 & 47,11 & 40,42 & 51,45 \\
apenas & Pessoal ocupado & 527 & 444 & 549 & 472 & 491 \\
Patentes & Tempo de estudo & 7,66 & 8,15 & 8,21 & 8,46 & 8,69 \\
\hline Depositaram & VTI (R \$ milhões) & 113,3 & 166 & 216 & 220 & 273 \\
Marcas e & Pessoal ocupado & 1332 & 1372 & 1287 & 1007 & 1137 \\
Patentes & Tempo de estudo & 8,27 & 8,35 & 8,62 & 8,79 & 9,12 \\
\hline
\end{tabular}

Fonte: INPI, 2005; IBGE, 2005 (elaboração própria).

Nota: VTI (Valor da Transformação Industrial) em R\$ mil, PO (Pessoal Ocupado) e Rem (Remuneração) em R\$

Um olhar mais atento na tabela 6 observa também que as variáveis obedecem a uma hierarquia pelo tipo de firma. Portanto, há indícios de que firmas que possuem marcas e patentes no INPI são maiores em VTI, empregam mais e seus funcionários são mais qualificados. 
As estatísticas descritivas proporcionam uma visão geral das diferenças entre as firmas. Porém, para se alcançar o objetivo do trabalho, é necessário isolar o efeito das outras variáveis que influenciam o desempenho das firmas. Para tanto, um modelo econométrico foi construído justamente para separar esse efeito. Os ganhos de produtividade das firmas com perfil mais inovador, que só adotam patentes, são de 7,1\% (no período 1998-2002) em relação a firmas que não adotam nenhuma estratégia. Entre as firmas que tem como estratégia trabalhar em cima da percepção do consumidor, que só depositam marcas, o aumento da produtividade é de 6,3\% em igual período.

Há evidências, portanto, de que marcas e patentes afetam a produtividade das firmas, o que reforça a necessidade de investimentos para tornar mais eficiente a operação do sistema de propriedade intelectual. É importante enfatizar que os resultados empíricos devem ser considerados um passo inicial no sentido de esclarecer alguns pontos a respeito da propriedade intelectual. À medida que novas informações forem disponibilizadas, naturalmente o presente estudo poderá ser revisitado e novas conclusões poderão ser extraídas. 